\title{
The Philosophical Foundations of Technological and Engineering Literacy
}

\section{Dr. R. Alan Cheville, Bucknell University}

R. Alan Cheville studied optoelectronics and ultrafast optics at Rice University, followed by 14 years as a faculty member at Oklahoma State University working on terahertz frequencies and engineering education. While at Oklahoma State, he developed courses in photonics and engineering design. After serving for two and a half years as a program director in engineering education at the National Science Foundation, he took a chair position in electrical engineering at Bucknell University. He is currently interested in engineering design education, engineering education policy, and the philosophy of engineering education.

\section{Dr. John Heywood, Trinity College-Dublin}

John Heywood is Professorial Fellow Emeritus of Trinity College Dublin- The University of Dublin. He is a Fellow of ASEE and Life Fellow of IEEE. he is an Honorary Fellow of the Institution of Engineers of Ireland. He has special interest in education for the professions and the role of professions in society. $\mathrm{He}$ is author of Engineering Education. Research and Development in Curriculum and Instruction. His most recent book is The assessment of learning in Engineering Education Practice and Policy. IEEE Press/Wiley. 


\title{
The Philosophical Foundations of Technological and Engineering Literacy
}

\begin{abstract}
The purpose of this paper is to discuss the importance of philosophy in discussions of technological literacy, and to point out that actionable definitions of technological literacy are not possible without philosophy. Technological literacy has been broadly conceived as relating to the designed world, which exists in conjunction with the natural and social worlds. Definitions of technology tacitly include the social world since social institutions produce technologies, governments regulate them, and engineers design them. Within this broad sphere, however, there are competing definitions of technological literacy that confuse the issue of how to best develop technological literacy in students through education. When one also considers engineering literacy, scientific literacy, math literacy and information literacy and the more recent push for economic and media literacy, these confusions are magnified.
\end{abstract}

To make sense of the many definitions of technological literacy it helps to look broadly at the groups that promote them. Each group has an explicit or tacit epistemology, and considering the definitions that arise from these views help to illuminate the underlying aims and objectives of teaching technological or engineering literacy. Here we briefly look at five perspectives: understanding technology in society, training students to manage technology in their lives, the need to have a technically literate workforce, philosophy of technology, and engineering. While each viewpoint has underlying aims and philosophies, the perspective of understanding technology in society provides a sufficiently expansive view so that meaningful problems can be posed and addressed by students. We explore some of the problems this view suggests and find that technological literacy can be taught as a transdisciplinary area of study (science, technology, and society programs), an area of philosophical inquiry (philosophy of technology), or in ways that organize inquiry across disciplines so students develop a personal philosophy.

\section{Background}

Interest in technological literacy as a concept has grown since the late 1950's. Krupczak and Blake (Blake \& Krupczak Jr., 2014) have charted development of the concept, looking particularly at the intersection of technological literacy with engineering literacy. It should be noted that the term "technological literacy" is more commonly used in the United States than other nations. A sense of how technological literacy has become more prevalent in conversations on education can be seen by looking at the word frequency of the term using the Ngram viewing tool (Google, 2010). While this tool has significant biases and limitations (Pechenick, Danforth, \& Dodds, 2015) the relatively high representation of scientific and technical literature in the corpus and the fact that "technological literacy" has a specific meaning that is not generally found in fiction permits a qualitative view of the rise in use of the term over a time frame of decades, as shown in Figure 1. 


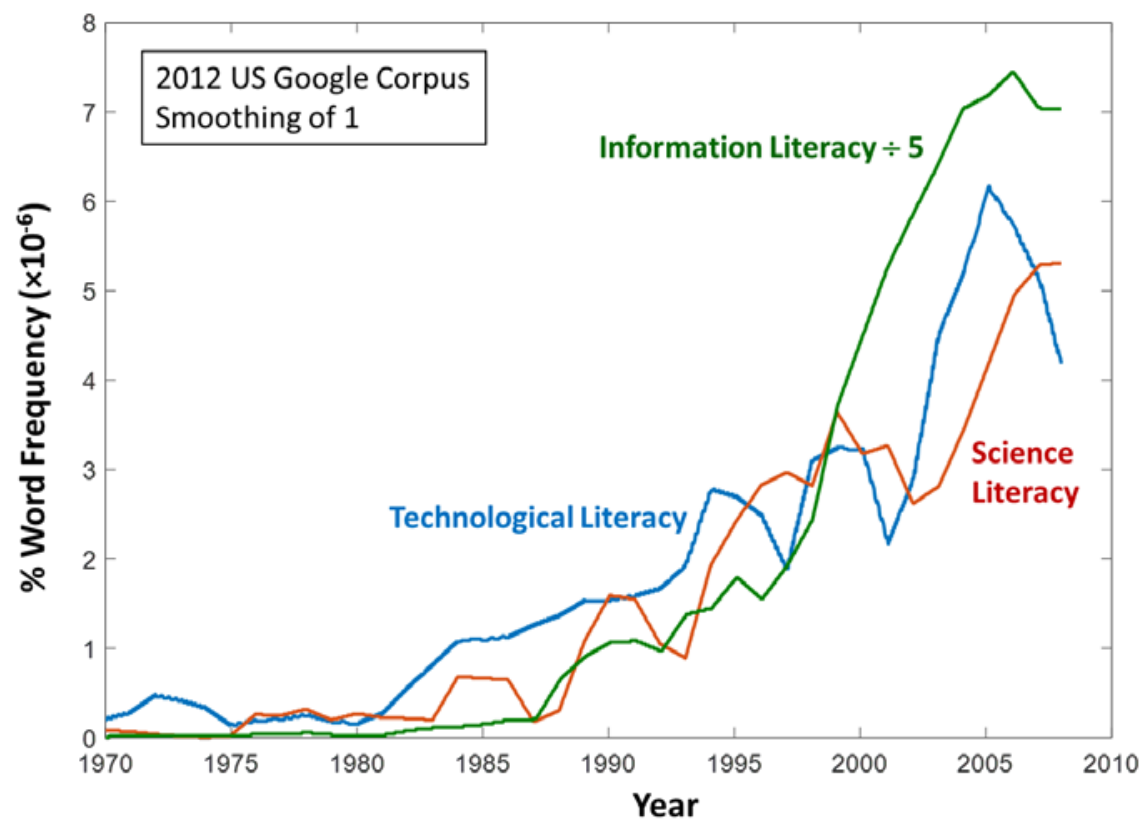

Figure 1: Google NGram word frequency vs. time graph of the terms "technological literacy", "science literacy", and "information literacy” (value divided by five) for 2012 dataset of American English with a smoothing of 1 for the time period 1970 - 2008.

The term technological literacy seems to have first come into use around the 1950's where it was used more by happenstance than deliberately. Before 1980 technological literacy most often referred to the benefits of, or need for: vocational education, skills for living in a world with rapid technological change, and to denote measures of technical competence. The steady rise starting around 1980 coincides with the time that personal computers became both popular and affordable; for example the IBM PC was introduced in 1981. The accessibility of technology to all age groups has only grown since then (Mawson, 2007). The 1980's was also the decade technological literacy began to come under increasing consideration in higher education by policy makers (The Committee to Idenfity Critical Issues in Federal Support for Science and Technology, 1986), foundations such as Sloan (Florman, 1987), and the AAAS through Project 2061 (Rutherford, 1989).

The 1990's saw increasing interest in technological literacy at the policy level (The Board for Engineering Education, 1994) where elements in government began to consider the role of technological literacy as a requirement for broad education and elements of technological literacy were integrated into the National Science Education Standards (National Research Council, 1996). The use of the term became even more prevalent in the US after 2000 when it was extended to K-12 education with the introduction of No Child Left Behind. This farreaching legislation required schools to use technology to increase student achievement, ensure students were technologically literate by the completion of the eighth grade, and have teachers to adopt technology in the classroom (Knezek, 2003). The International Technology Education Association (now ITEEA), a group that had represented industrial arts for decades, developed technological literacy standards as they sought to reframe their relevance in a changing educational environment. During the same period the National Academy of 
Engineering released several influential publications that broadly sought to clarify technological literacy and its distinction from engineering literacy (Garmire \& Pearson, 2006; National Academy of Engineering \& National Research Council, 2002).

It is worth noting that a parallel term, "scientific literacy" is used with roughly the same frequency and the same rapid rise from the 1980 onward, see Figure 1. Both of these terms are often associated with perceived crises in science, engineering, or technology education. Such crises have been discussed within engineering in the United States for almost as long as there have been engineering programs (Cheville, 2014) due to the perception that STEM education is closely tied to economic growth and security (Committee on Prospering in the Global Economy of the 21st Century, 2006, 2010). Despite the large role engineering plays in the economy (Carnevale, Smith, \& Melton, 2011) there are far fewer references to “engineering literacy”, a term promoted by ASEE's Technological and Engineering Literacy and Philosophy of Engineering Division (Krupczak Jr. et al., 2012). Other terms related to technological literacy are "information literacy" which is about five to ten times more prevalent, "math literacy”, and more recently "media literacy”.

The increasing interest in technological literacy has led to many attempts to define what technological literacy actually is (Blake \& Krupczak Jr., 2014; Cheek, 1992; Dakers, 2006; Dyrenfurth, 1992; Gagel, 1997). Converging to a single, concise definition has been difficult. Rather than precise definitions the existing literature focuses more on sets of descriptors that are adopted by particular communities such as K-12 educators, STS researchers, or policy makers. In the remainder of this paper we briefly contrast existing descriptions and discuss the positions and belief systems underlying these definitions, showing that each adopts particular philosophies. We then explore several reasons for why technological literacy may be difficult to define, finding that technological literacy is better identified as a set of issues or problems rather than definitions. In this analysis we first assume that every attempt to define technological literacy is made in support of an existing belief system. Second, we recognize that the needs of educators who operate under real and pressing constraints are different from those who view technological literacy at a distance from the reality of teaching.

\section{Disparate Definitions of Technological Literacy}

As technological literacy has come to drive high stakes educational outcomes, attempts to define what is meant by the term have increased. Here we focus on a set of definitions created by different groups who have some stake in defining technological literacy. Although we discuss them separately, in reality these groups are not isolated; a Venn diagram would be highly intersecting.

Science, Technology, and Society: One group consists of the researchers and academics who work in the area broadly defined as Science, Technology, and Society (STS). This group seeks to understand relationships between, and the impacts of, intersections of social and technical systems. They also engage with history, sociology, and philosophy, as exemplified by the work of Mitcham (Mitcham, 1994), as they seek to understand how the value systems 
that drive technology's impact with society. An early review of curricular frameworks that incorporated STS content or ideas identified 29 descriptors drawn from four general categories - knowledge, skills, ethics and values, and action/involvement - that can be applied to many forms of literacy (Cheek, 1992). A later study (Gagel, 1997) defined technological literacy as being able to: "(a) accommodate and cope with rapid and continuous technological change, (b) generate creative and innovative solutions for technological problems, (c) act through technological knowledge both effectively and efficiently, and (d) assess technology and its involvement with the human lifeworld judiciously." Generally STS-derived definitions of technological literacy address the need to educate individuals for living in a technologically mediated world and are system oriented, involve elements of the ethical and moral dimensions of society, and are both critical and integrative, questioning the often accepted formula that "science + technology + democracy $(+$ capitalism $)+$ education = progress" $($ Wonacott, 2001). In essence the STS perspective is ontological, exploring how technology interfaces with and is an organizing force in society.

Educators: Another set of definitions arise from educators and the organizations that represent them. These definitions tend to be more specific and actionable since they are often intended to guide standards development. When the No Child Left Behind legislation was being developed, the International Technology Educators Association (ITEA, now ITEEA) framed five broad standards which informed later work: understanding the nature of technology, understanding of technology and society, understanding of design, abilities for a technological world, and understanding of the designed world (Blake \& Krupczak Jr., 2014). More recent definitions are from the International Society for Technology in Education (ISTE) and the State Educational Technology Directors Association (SETDA) which include corporate members from the technology sector. ISTE's standards for technological literacy in 2007 had six elements: creativity and innovation; communication and collaboration; research and information fluency; critical thinking, problem solving, and decision making; digital citizenship; and technology operations and concepts. The updated 2016 definitions focus on more ontological elements: empowered learner, digital citizen, knowledge constructor, innovative designer, computational thinker, creative communicator, and global collaborator. SETDA defines technological literacy as "The ability to responsibly use appropriate technology to communicate, solve problems, and access, manage, integrate, evaluate, and create information to improve learning in all subject areas and to acquire lifelong knowledge and skills in the 21st century."

These definitions of technological literacy influenced the Next Generation Science Standards in the US (Next Generation Science Standards, 2013) which identify as core ideas that science and engineering are synergistic in developing new technologies and scientific insights, that technology development impacts human society, and that engineering is the process that creates technology. Overall definitions that emerge from the education realm can be broadly classified as either developing skills to effectively use technology for some other end (e.g. educational, economic, self-determined, etc.), having understanding of technology as a thing-in-itself, or developing knowledge, skills, and attitudes that allow an individual to function within an increasingly technological world. 
Policy Makers: Another set of definitions arises from policy makers interested in the needs of the future workforce. Since technology plays an increasingly important role in economic growth, employers need technically literate employees. Several decades ago Dyrenfurth (Dyrenfurth, 1992) reported that employability skills closely overlapped technological literacy, reporting on three studies that found similar skills were needed by employers. More recently Carnevale (Carnevale et al., 2011) explored knowledge, skills, abilities, values, and interests associated with STEM careers finding that as technology drives more of the economy the skills associated with technological literacy are in demand in all sectors (Foroohar, 2017).

The most comprehensive attempt to define technological literacy in the policy realm in the US was Technically Speaking released by the National Academy of Engineering in 2002. The report was written for a broad audience and proposed a similarly broad definition of technological literacy that focused on knowledge, ways of thinking and acting, and capabilities which were seen as orthogonal dimensions of technological literacy, Figure 2. The report emphasized day-to-day interactions with technology, distinguishing technological literacy (living with technology) from technological competence (working with technology). The report makes a strong policy case for technological literacy, framing it as being needed in democratic systems to inform decisions about technology, support the economy, and create new jobs and was highly supportive of federal actions to build technological literacy including creating standards in K-12 education, measuring technological literacy achievements, and supporting technology outreach to media and citizens.

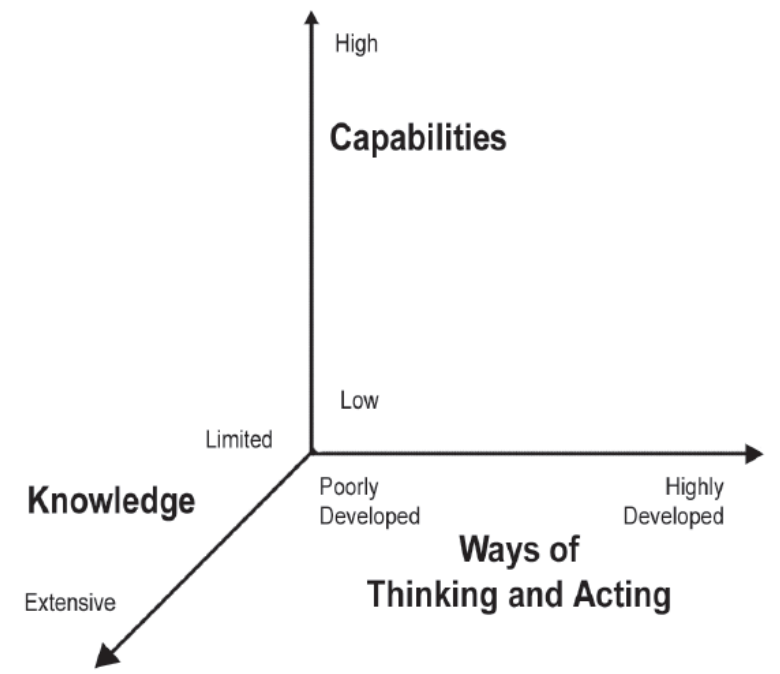

Figure 2: Dimensions of technological literacy reproduced from the National Academy of Engineering publication Technically Speaking.

Elements of technological literacy were also highlighted with a much more urgent tone in the Rising Above the Gathering Storm reports from the National Academies (Committee on Prospering in the Global Economy of the 21st Century, 2006, 2010). In summary, technological literacy is seen in the policy and workforce realm as a sets of knowledges, skills, and mindsets_-both specialized and general-that drive civic engagement in democratic societies and are increasingly important for economic growth. These definitions 
focus on the attributes individuals will need to engage in the society envisioned by leaders in the political and economic spheres, explore the "why" questions of technological literacy, and provide information that justify policy actions and investments in education.

Philosophy: More recently technology has become a more recognized area in philosophy, with some corresponding attention to technological literacy. In actuality technological literacy has been addressed by philosophers from at least the time of the ancient Greeks; our word for technology comes from the Greek words techne (knowledge of craft) + logos (reason or account). Aristotle defined techne as teachable skills which likely laid a foundation for the concept of technological literacy. Despite the notion of techne as being teachable many authors have noted that developing a definition - the action of defining the nature of a thing or the meaning of a word (Oxford English Dictionary, 1989)—of technological literacy has proven difficult, and may not be possible (Blake \& Krupczak Jr., 2014; Dakers, 2006, 2014; Mitcham, 1994). The lack of a widely accepted definition has not been for want of trying to establish a philosophical basis for technology or technological literacy (Mitcham, 1994). Definitions of technological literacy have been broadly considered in the philosophy of technology community. For example collections edited by Dakers (Dakers, 2006, 2014) explore the epistemologies implied by different views of technological literacy. Feenberg (Feenberg, 2006) argues that while the ancient Greeks saw techne as bringing in to existence an idea or object through an artefact, as humanity has refined our capability to change the world the Greek ideas of existence (that something physically exists in the world) and essence (the underlying rationale for a thing's state of being) have become decoupled. This decoupling, i.e. disconnect of artefacts from the natural world, has led to means being separated from ends leading to a crisis for civilization (MacIntyre, 2009). It may be that our disconnect from the essence of existence triggers a need for control that is expressed through mastering technology. Feenberg framed technology dialectically on two axes: (1) whether technology reflects or stands separate from human values, and (2) whether technological developments can be managed by humans or are ultimately incontrollable (Feenberg, 2006; Mitcham, 1994). Mapping definitions to these axes indicates that in a broad sense the policy and education views see technology as advancing regardless of human volition. Policymakers view technology as manageable while many educators take the view that humans must adapt to technology. The STS view sees technology as more value-laden, magnifying the impact of existing societal structures. In summary rather than seeking to clearly define technological literacy philosophers have offered frameworks to consider its meaning, impact, and self-consistency.

Engineering Literacy: Recently engineering literacy has begun to be distinguished from technological literacy. Krupczak and Blake (2015) reviewed definitions of both technological and engineering literacy and found that while they have converged over time, engineering literacy may be thought of as a branch from technological literacy. One way to differentiate engineering from technological literacy is to view technology as a set of products and engineering as an active boundary-crossing creative process (Blake \& Krupczak Jr., 2014; Krupczak Jr. et al., 2012). In his ethnography of practicing engineers Bucciarelli captures this perspective as he describes how engineers actively create technological artifacts 
in a space defined by constraints dictated by existing technologies, market forces, and the micro- and macro- social environments in which they work (Bucciarelli, 1996). Other explorations of the actual practice of engineering (Trevelyan, 2014; Vinck, 2003) similarly illustrate how engineering is an active process of navigating the various domains that influence technological development. Thus as Krupczak and Blake indicate, engineering literacy is a more precise and focused set of skills that let individuals successfully navigate the influencing spaces when creating technology. While definitions of engineering literacy are still evolving, it is distinguished by its process orientation and having a more definable set of conceptual, procedural, practical, and dispositional knowledge (Billet, 2009).

In summary the definitions of technological literacy that emerge from different groups have considerable overlap but differ in several ways. While STS takes an ontological and systemic view, education looks for pragmatic and actionable ways to teach technological literacy as well as the characteristics of technologically literate individuals. The definitions focused on workforce and policy issues tend to be forward looking, philosophers seek to frame the issues surrounding technological literacy, while engineers have branched out in a more procedural direction. The above summary drastically oversimplifies the rich discussions that have taken place in each of these domains. Each viewpoint captures necessary aspects of technological literacy that represent the interests and needs of each group, but in aggregate the various definitions proposed illustrate that what seems to be a simple idea-teaching students to flourish in a technological world-is anything but simple. Attempting to define technological literacy in a way that informs curriculum seems to either lead to its own discipline or a set of disparate knowledges and skills that lack an underlying coherent structure. In the next section we explore why technological literacy has proven so difficult to define actionably.

\section{Philosophical Explorations of Technological Literacy}

While defining technological literacy is a somewhat esoteric task, each of the above definitions are intended to influence how students are educated and thus have implicit conceptions of the future and the individual's role in it. Each of the groups offering definitions of technical literacy have particular perspectives on the future that make a valid claim on educational resources and students' time. This section explores reasons why the artefacts (technology) and processes (engineering) of a human designed world may be difficult to teach as literacies; i.e. why technological literacy suffers from epistemological challenges. These challenges are framed through four speculative lenses which emerged from reading the positions on technological and engineering literacy taken by different groups. Each of these frames is designed to critique established epistemologies of technological or engineering literacy and by doing so help refine the essential elements of what is meant by "literacies".

Frame One: Technological Literacy as a Desired Future State Rather than Teachable Knowledge

The above views of technological literacy might be better be viewed as a broad set of competencies promoted by groups within society to achieve some envisioned future state 
rather than as a set of definitions. In other words, as in Saxe's poem The Blind Men and the Elephant, each group promotes educational goals related to technological literacy from a particular belief system and ideology driven by their view of a future world. The question then is whether there is in fact an elephant? That is, will further refinement of a definition result in a defined set of knowledges or will the desires for the future always remain inchoate? While all education is a projection of hope into the future, implementing practical education programs requires that an area of knowledge be able to be defined, developed, and maintained. Viewing technological literacy as a desired future state rather than a necessary content area brings up long-standing questions on the proper roles and limits of education in preparing students for democratic societies as well as what degree of agency students and parents should be granted.

\section{Frame Two: Technological Literacy as Overdetermined}

The epistemological bases of engineering differ from the rationalist paradigm that drives much STEM education (Goldman, 2004). Engineering (as well as education) seeks satisfactory solutions where appropriateness is determined by highly contingent value judgments based on the specific contexts and constraints. Looking at technological literacy from this perspective definitions may be thought of as one form of constraints. In engineering an overdetermined system is one in which there are more equations that bound (constrain) the problem than there are unknowns, which are indeterminate. Such systems generally are not solvable. The drive towards actionable definitions of technological literacy, i.e. that can inform curriculum, may in fact over-constrain the solution space of effective teaching.

One reason definitions might be over-constraining is due to the rapid, perhaps exponential, growth of knowledge. It somewhat ironic to note that much of the growth of knowledge is caused or abetted by technology. A similar constraint is that the rate of change of technology is faster than educational systems can respond so at some level there will always be a game of catch up in defining technological literacies. Waks points out that initial definitions of technological literacy that emerged in the 1970's are no longer valid given the effect of globalization and communication networks in the early part of the $21^{\text {st }}$ century (Waks, 2006). These changes particularly impact definitions that emerge from the workforce / policy realm. For example Dyrenfurth’s Venn diagram of the overlap of technological literacy other skills requires constant updating (Dyrenfurth, 1992). Again, all fields of education need to do this to some degree but the problem is particularly acute in technological literacy. Given that in current political climates there are limited resources to fund new educational initiatives there is then pressure on schools to tightly define any new programs. This is turn means that that technological literacy needs to be well defined, creating somewhat of a vicious cycle. Adding to these constraints are the fact that technology by its nature is ephemeral so providing technology to students in turn will generate replacement, upgrade, and training costs. 
Frame Three: Is Technology Beneficial or Inimical to Eudaimonia?

What has triggered the rise in interest in technological literacy shown Figure 1? What is it that makes technological literacy important to address in formal schooling at this point in time given that people have been confronted with adapting to new technologies from the dawn of civilization? One popular perspective, often captured in dystopian fiction, is the sense that technology can outpace human capabilities to manage it. More utopian views are captured in the idea of the "singularity". Here the exponential growth of computing capability (or other technologies) is predicted to result in an explosion of technological growth; this idea has been treated as dogma by some technologists (Lanier, 2013). Both these views are reflected in the above definitions of technological literacy.

The human for or against technology perspective can be framed by altering the three axes of technological literacy originally from Technically Speaking (National Academy of Engineering \& National Research Council, 2002) which is shown in Figure 2. If the Cartesian (no pun intended) system is extended to include the negative quadrants the resultant coordinates might appear as in Figure 3. Here the negative directions represent human, pretechnological, ways of knowing, doing, and acting while the positive directions represent technology mediated ways of knowing and doing. Unlike the educational and policy views of technological literacy that see technology as always adding to human capability, this framework posits that human and technological values need to be considered explicitly against each other. An example is the shift in ISTE standards from 2007 to 2016 which shifted technology from a separate learning outcome to integrating technology into personal ways of being, a form of technological determinism.

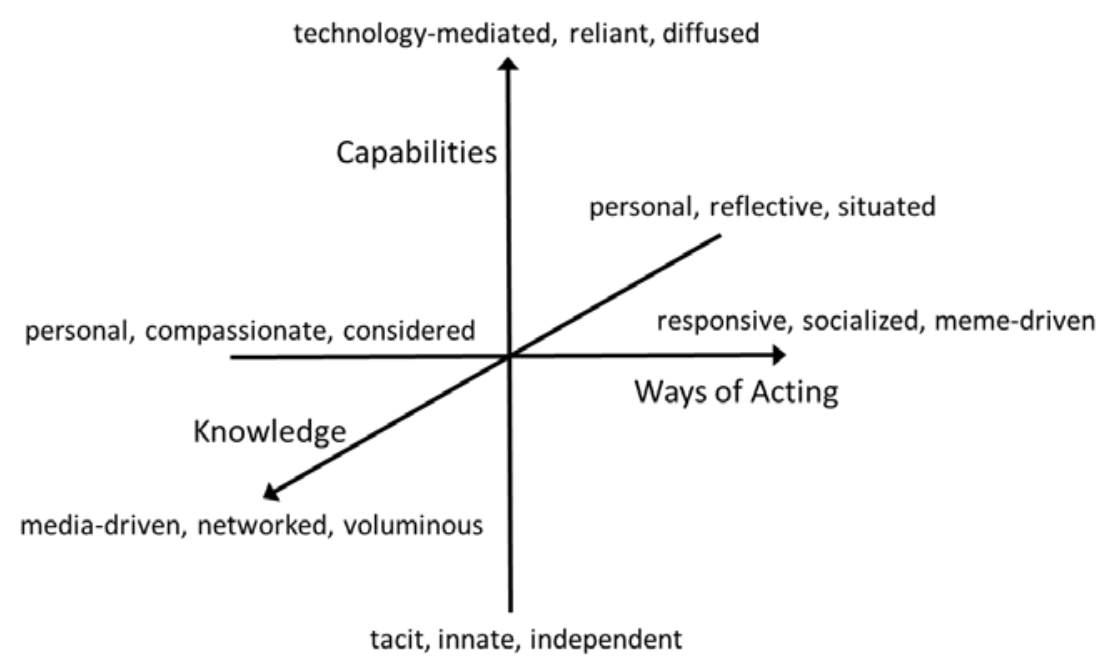

Figure 3: Expansion of the three axes of Technically Speaking into human and technological realms.

In this framing, technological literacy is not about how to educate and comport oneself with technology, but rather how to make choices about the extent to, and ways through which, one wishes to engage with technology. For example to use many mobile applications one assigns rights to access of private data to the provider of the technology (Lanier, 2013); these rights and the implications of EULAs are not usually transparent. Similarly while computers in K- 
12 were initially seen as a useful tool for learning, now we are having to deal with technology as something we need to train students to defend themselves against (child pornography, cyber-bullying).

\section{Frame Four: Engineering and Plato's Cave}

Krupczak and Blake (Blake \& Krupczak Jr., 2014) make a distinction between technological and engineering literacy as one of product vs. process. Those who are technologically literate understand the use, implications, and impact of technology on the human and social worlds. Those who possess engineering literacy navigate the mathematical, physical, social, and human worlds in the act of creating technology. Another way to frame this distinction is viewing education from the perspective of gnosis and episteme (Davis, 2009). From the gnosis view while technology is designed by humans it increasingly exists independent of human intention and intervention and serves, as nature did in earlier societies, as a driver of human adaptation and evolution (Illich, 2001). The epistemic view asserts the craft of technology is understandable, can be taught, and in the Aristotelian sense such teaching develops the intellectual virtue of techne.

The distinction between gnosis and episteme frames technology in a way similar to the cave in Plato's famous allegory. Technological literacy teaches students to divine meaning from artifacts of technology (the shadows being cast) while engineering literacy seeks to create more engaging artifacts (shine light that can cast better shadows). This analogy seems particularly apropos given the amount of time people spend staring into screens. This view raises several epistemological challenges. One has to do with the nature of techne where the virtue in the thing made arises from the maker. Because only those who understand a craft can perceive its intent or impact techne can be seen an existential threat to societies (Cuomo, 2007). Can engineering literacy be taught without professional ethics? Can it be taught without philosophy? Another challenge is that both the gnosis and episteme views present incomplete pictures of reality, so that trust is needed for society to function. This trust has traditionally been supported through viewing engineering as a profession with responsibility for public welfare. Yet Ivan Illich (Illich, 2001) has written that as technology advances the gap between those who use and create technology widens and humans respond by becoming more specialized. More distance and less insight typically leads to less trust; look at the questions over how technology may have influenced the election in the US in 2016. Should an aspect of technological literacy then be focused on developing trust for the engineering profession? Many would disagree with this position.

\section{Discussion and Possible Actions}

The previous section laid out four frames that explored reasons technological literacy has proven difficult to operationalize. In brief they were that: (i) technological literacy is not as much a branch of knowledge but an envisioned future state, (ii) the nature of technology over-constrains efforts to teach it effectively, (iii) technological literacy should teach students to know how to resist as well as live with or for technology, and (iv) that the advance of technology increasingly separates gnosis and episteme. This section seeks to explore the insights these framings of the challenge inherent to defining technological literacy can 
provide. The goal is to suggest ways to move toward actionable curricular changes, difficult as they may be to accomplish.

One tension that emerges from the first and fourth frames arises from categorizing the day-today activities of living in a world being changed by technology as literacy; i.e. having knowledge of letters or book learning. With such a categorization the focus of technological literacy may be too much on the explicit and a priori forms of knowledge most traditional schooling addresses. By framing the goals of technological literacy in an a posteriori fashion that addresses both tacit forms of knowing and students' lived experiences it may be possible to better understand the various perspectives on technological, engineering, and the other literacies being proposed to help people live eudaimonic lives in a created world.

In this case it seems more productive to consider technological literacy as a form of inquiry and discourse that allows a student to make decisions that affect their future rather than as required knowledge in a disciplinary sense (Frezza, Nordquest, \& Moodey, 2013). Technological literacy thus returns back into the realm of philosophy. This approach has been taken in academic discussions (Dakers, 2006, 2014) and characterizes many conversations on technological literacy, which seem to be converging over time (Blake \& Krupczak Jr., 2014). Heywood also explicitly addresses this issue through exploring the work of Alfred North Whitehead (Heywood, 2014a).

The issue of teaching technological literacy as inquiry and discourse can be informed by the thinking of Cardinal Newman laid out in The Idea of a University (Newman, 1852).

Newman articulated that the role of the university is to present knowledge as universal rather than a collection of discrete, disconnected subjects. The correct way to accomplish this was in development of an "architectonic science" or a philosophy whose role was to synthesize disparate realms of knowledge (see Discourses IV and VII). In Newman's view any discipline necessarily sees the world narrowly, and each perspective is correct in some aspects and wrong in others. The value of education arises not from disciplinary knowledge, but rather from interactions between individuals from different backgrounds in both academic and social endeavors. Since the various aspects of technological literacy fall within established disciplines, one way to develop technological literacy is to provide the space and time to bring together different perspectives either in formal or informal educational environments (Heywood, 2014b). In this case the definitions offered by STS and philosophy of technology provide guidance on teaching technological literacy since they take a more systemic view. Perhaps developing a systemic view focused on interconnection is technological literacy?

Since the mid $19^{\text {th }}$ century when Newman was writing about the purpose of education universities have become more specialized, the number of disciplines has grown, and universities have become larger both in terms of student population and through the number of opportunities to build specific affinity groups. If developing technological literacy is viewed as a teaching a defined content area then these trends may be beneficial as the rise of specialized STS programs indicates. If, however, becoming technologically literate is seen as 
a process of personal growth catalyzed by participating in discourse in a community, then these trends-along with narrowing of the area of knowledge any one faculty member "professes" to-may undermine developing broad literacies. As discussed in the second frame this increasing specialization acts to speed up technological development and leads to the growth of knowledge which increases the difficulty of teaching technological literacy.

One solution to the above issues is to make educational systems more agile so they can keep up with the societal changes caused by technology; this is easier said than done. Changes in curriculum or educational structure - which are difficult to accomplish in practice-may go far in this direction but are also difficult to implement. There are some current programs that have moved in this direction. For example Olin College in the United States has a structure that follows the Newman model than more traditional engineering programs as does the Iron Range Program affiliated with Minnesota State, Mankato. Another option would be to decouple technological literacy from formal education. Here students would receive an education in a discipline but gain technological literacy through interactions in Maker- or Hacker-Spaces (Blikstein, Kabayadondo, Martin, \& Fields, 2017; Heywood \& Owen, 1990).

Yet another option may be to bridge cultures that already exist on campus. Engineering and technology faculty often act as cheerleaders for their disciplines, a stance supported by the crisis STEM narratives that emerge from groups who seek to influence policy makers. However the humanities and social sciences often are more sceptical of the science + technology + democracy $(+$ capitalism $)+$ education = progress $($ Wonacott, 2001) narrative. These disciplines also value discussion-based approaches to learning and have expertise on engaging students in such discussions. Such an approach is implemented at many universities with varying levels of success through interdisciplinary courses. With respect to the third human vs. technology frame, interdisciplinary approaches may be successful at getting students to more mindfully develop their relationship with technology as well as develop skills that give them more mastery over the technologies they do choose to engage with. In programs such as this technological literacy would not be taught as a set of defined competencies, but rather by posing meaningful problems that students would encounter in life. These problems - both caused and solved by technology-frame discourses that would inform students own responses to an increasingly technological world.

\section{Conclusions}

Throughout this paper we have taken a critical look at definitions of technological literacy that emerge from various groups. These definitions reflect the perspectives and aspirations of the groups that propose them but introduce epistemological and practical challenges. The epistemological challenges arise from the inherent difficulties of describing human and social interactions with technology as a literacy, the fact it is difficult to define a coherent content area that is not so broad as to be a discipline in itself, and the rapidly changing nature of technology. The practical challenges have to do with resource constraints and the increasingly fragmented nature of educational programs. These constraints limit the ability of educational systems to encompass multiple definitions and literacies. 
We argue that to address these challenges technological literacy will need to adopt an $a$ posteriori framework rather than the explicit and a priori epistemology currently used in many educational institutions. By framing the goals of technological literacy as developing a personal philosophy that informs one's action it becomes necessary to include elements of ethics, ontology, and metaphysics. Ethics arises since to understand our behaviour in relation to technology is to understand our beliefs (needs); without such understanding there is no guarantee the changes we make to the world will be for the better. Since technology increasingly impacts our and others' perceptions of reality, ontology is needed to negotiate our own relationship with technology and understand how letting technology change our human capabilities impacts our sense of being. In approaching technological literacy as an architectonic science there is a need to integrate technological and engineering literacy. Since design - the act of creating technology — is embedded in the social world, the development of the technologically (or engineering) literate individual cannot take place outside of social relationships. It is through these relationships that we become aware of our being which impacts not only on our beliefs but our behaviour (MacMurray, 1957, 1961).

Throughout all human folklore and literature meddling with forces that are beyond one's own capabilities for understanding has clear, and often negative, personal and ethical consequences. Technological literacy, which seeks to provide knowledge, is one more way of controlling these forces that increasingly affect our lives. Engineers who contribute to the design of world-changing technologies have some conception of what "would be good if it did exist” (James, 1912) and thus address metaphysical questions. Thus the increasingly alignment between technological and engineering literacy implies a strong obligation to develop a philosophy that drives our value systems. Only by including philosophy in the definitions of technological literacy can we explore the issues that developments in technology pose as for its control over knowledge, its control over ourselves, and what behaviours are permissible and not permissible.

Billet, S. (2009). Realising the educational worth of integrating work experiences in higher education. Stud. in Higher Educ., 34(7), 827-843.

Blake, J., \& Krupczak Jr., J. (2014). Distinguishing Engineering and Technological Literacy. Philosophical Perspectives on Engineering and Technology Literacy, 1, 3-25.

Blikstein, P., Kabayadondo, Z., Martin, A., \& Fields, D. (2017). An Assessment Instrument of Technological Literacies in Makerspaces and FabLabs. Journal of Engineering Education, 106(1), 149-175.

Bucciarelli, L. (1996). Designing Engineers. Cambridge, MA: The MIT Press

Carnevale, A. P., Smith, N., \& Melton, M. (2011). STEM. Washington, DC: Center on Education and the Workforce, Georgetown University.

Cheek, D. W. (1992). Thinking Constructively about Science, Technology, and Science Education. Albany, NY: State University of New York Press.

Cheville, R. A. (2014). Defining Engineering Education. Paper presented at the American Society for Engineering Education, Indianapolis, IN.

Committee on Prospering in the Global Economy of the 21st Century. (2006). Rising Above The Gathering Storm: Energizing and Employing America for a Brighter Economic Future. Washington, DC: National Academy of Sciences, National Academy of Engineering, Institute of Medicine.

Committee on Prospering in the Global Economy of the 21st Century. (2010). Rising Above the Gathering Storm, Revisited: Rapidly Approaching Category 5. Washington, DC: National Academies. 
Cuomo, S. (2007). Technology and culture in Greek and Roman antiquity. Cambridge UK: Cambridge University Press.

Dakers, J. R. (Ed.). (2006). Defining Technological Literacy, Towards an Epistemological Framework. New York: Palgrave-Macmillan.

Dakers, J. R. (Ed.). (2014). New Frontiers in Technological Literacy: Breaking with the Past. New York: Palgrave-Macmillan.

Davis, B. (2009). Inventions of Teaching: A Genealogy. New York: Routledge.

Dyrenfurth, M. J. (1992). The Structure of Technical Competence. Paper presented at the International Conference on Technology Education, Weimar, Germany.

Feenberg, A. (2006). What is the Philsophy of Technology? In J. R. Dakers (Ed.), Defining Technological Literacy: Towards an Epistemological Framework. New York: Palgrave-Macmillan.

Florman, S. C. (1987). The Civilized Engineer. New York: St. Martin's Griffin.

Foroohar, R. (2017, March 12). The silver thread of technology that runs through future jobs, Financial Times.

Frezza, S., Nordquest, D., \& Moodey, R. (2013). Knowledge-generation epistemology and the foundations of engineering. Paper presented at the Frontiers in Education, Oklahoma City.

Gagel, C. W. (1997). Literacy and Technology: Reflections and Insights for Technological Literacy. Journal of Industrial Teacher Education, 34, 6-34.

Garmire, E., \& Pearson, G. (2006). Tech Tally: Approaches to Assessing Technological Literacy. Washington DC: National Academy of Engineering.

Goldman, S. L. (2004). Why we need a philosophy of engineering: a work in progress. Interdisciplinary Science Reviews, 29, 163-176.

Google. (2010). Google Books NGram Viewer. Retrieved January, 2012, from http://books.google.com/ngrams/

Heywood, J. (2014a). Defining engineering and technological literacies within the framework of liberal education: implications for the curriculum. Paper presented at the American Society for Engineering Education, Indianapolis, IN.

Heywood, J. (2014b). Engineering at the Crossroads. Implication for Educational Policy Makers. In B. M. Olds \& A. Johri (Eds.), Cambridge Handbook of Engineering Education. New York: Cambridge University Press.

Heywood, J., \& Owen, S. (1990). Transition Technology in Ireland: An Experimental Course. International Journal of Technology and Design Education, 1(1), 21-32.

Illich, I. (2001). Tools for Conviviality. London: Marion Boyar.

James, William. (1912). The Will to Believe and other Essays in Popular Philosophy. New York: Longman, Greens, and Co.

Knezek, D. G. (2003). Technology and a Vision of LearningTechnology in Education: Reform Through the Implementation of Teaching and Learning Standards. Paper presented at the Educational Technology for Teacher Preparation and Certification. http://www.pearsonassessments.com/teacherlicensure/conference-onteaching/publications/educational-technology-for-teacher-preparation-and-certification.html

Krupczak Jr., Blake, J. W., Disney, K. A., Hilgarth, C. O., Libros, R., Mina, M., \& Walke, S. R. (2012). Defining Engineering and Technogical Literacy. Paper presented at the American Society of Engineering Education, San Antonio, TX.

Lanier, J. (2013). Who Owns the Future? New York: Simon \& Schuster.

MacIntyre, A. (2009). God, Philosophy, Universities. A History if the Catholic Philosophical Tradition. London: Continuum.

MacMurray, J. (1957). The Self as Agent. London: Faber \& Faber.

MacMurray, J. (1961). Persons in Relation. London: Faber \& Faber.

Mawson, B. (2007). Factors affecting learning in technology in the early years at school. Int. J. Tech. Des. Educ., 17(2), 253-269.

Mitcham, C. (1994). Thinking through technology: the path between engineering and philosophy. Chicago: University of Chicago Press.

National Academy of Engineering, \& National Research Council. (2002). Technically Speaking:Why All Americans Need to Know More About Technology. Washington, DC: National Academy of Engineering.

National Research Council. (1996). National Science Education Standards. Washington, D.C.: National Academy Press.

Newman, J. H. (1852). The Idea of a University Defined and Illustrated: In Nine Discourses Delivered to the Catholics of Dublin: Project Gutenberg.

Next Generation Science Standards. (2013). Next Generation Science Standards. Retrieved January, 2017, from http://nextgenscience.org/ 
Oxford English Dictionary. (Ed.) (1989) Oxford English Dictionary. Oxford University Press.

Pechenick, E. A., Danforth, C. M., \& Dodds, P. S. (2015). Characterizing the Google Books Corpus: Strong Limits to Inferences of Socio-Cultural and Linguistic Evolution. PLOS One, 10(10), e0137041. doi: 10.1371/journal.pone.0137041

Rutherford, J. S. (1989). Science for All Americans: Project 2061. New York: Oxford University Press. The Board for Engineering Education. (1994). Major Issues in Engineering Education. Washington, D.C.: National Research Council.

The Committee to Idenfity Critical Issues in Federal Support for Science and Technology. (1986). Federal Actions for Improving Research and Education. Washington, D. C.: National Academy of Engineering.

Trevelyan, J. (2014). The Making of an Expert Engineer. London: CRC Press.

Vinck, D. (Ed.). (2003). Everyday Engineering: An Ethnography of Design and Innovation. Cambridge, MA: MIT Press.

Waks, L. J. (2006). Rethinking Technological Literacy for the Global Network Era. In J. R. Dakers (Ed.), Defining Technological Literacy: Towards an Epistemological Framework. New York: PalgraveMacmillan.

Wonacott, E. (2001). Technological Literacy (Vol. 233): ERIC Clearinghouse on Adult, Career, and Vocational Education. 